Review

\title{
Contribution of Schinziophyton rautanenii to Sustainable Diets, Livelihood Needs and Environmental Sustainability in Southern Africa
}

\author{
Alfred Maroyi \\ Medicinal Plants and Economic Development (MPED) Research Centre, Department of Botany, \\ University of Fort Hare, Private Bag X1314, Alice 5700, South Africa; amaroyi@ufh.ac.za; Tel.: +27-71-9600326
}

Received: 16 January 2018; Accepted: 4 February 2018; Published: 26 February 2018

\begin{abstract}
Schinziophyton rautanenii is a multipurpose plant species in Southern Africa which provides numerous ecosystem goods and services. This review evaluated the contribution of the species to sustainable diets, livelihood needs and environmental sustainability throughout the geographical range of the species. The literature relevant to the study was obtained from scientific databases such as ScienceDirect, SciFinder, Pubmed, Google Scholar, Medline and SCOPUS. Literature was also obtained from the University of Fort Hare library, dissertation search engines like ProQuest, Open-thesis, OATD, and EThOS. S. rautanenii is an essential source of food, herbal medicines, income, oil, timber and wood. The species provides substantial health, economic and ecological benefits to local communities that depend on the species as a source of livelihood needs. This study represents a holistic view on multiple ecosystem goods and services that are derived from $S$. rautanenii forming an essential component of the 2030 Agenda for sustainable development goals (SDGs) adopted by the United Nations General Assembly. Use, cultivation and management of S. rautanenii in Southern Africa offers enormous potential for contributing to the fulfillment of the SDGs, resulting in improved food security, household nutrition and health, income, livelihoods, ecological balance, sustainable diets and food systems.
\end{abstract}

Keywords: ecosystem goods and services; environmental sustainability; livelihood needs; Schinziophyton rautanenii; Southern Africa; sustainable development goals; sustainable diets

\section{Introduction}

Sustainable use of plant biodiversity for food and medicines, as a source of other goods and ecosystem services play a crucial role in the fight against poverty, hunger and poor health and ensuring environmental sustainability while providing basic food and primary healthcare needs to local communities. Sustainable plant biodiversity management is central to the fulfillment of the 2030 Agenda for Sustainable Development Goals (SDGs), particularly the following [1]:

Goal 1: end poverty in all its forms everywhere,

Goal 2: end hunger, achieve food security and improved nutrition and promote sustainable agriculture,

Goal 3: ensure healthy lives and promote well-being for all at all ages,

Goal 12: ensure sustainable consumption and production patterns, and

Goal 15: protect, restore and promote sustainable use of terrestrial ecosystems, sustainably manage forest, combat desertification, and halt and reverse land degradation and halt biodiversity loss.

Use, cultivation and management of wild edible plant species in Southern Africa offers enormous potential for contributing to the fulfillment of the above-mentioned SDGs, resulting in improved food 
security, household nutrition and health, income, livelihoods, ecological balance, sustainable diets and food systems.

According to the Food and Agriculture Organization [2], "sustainable diets" are those diets with low environmental impacts which contribute to food and nutrition security and to healthy life for present and future generations. Sustainable diets are protective and respectful of biodiversity and ecosystems, culturally acceptable, accessible, economically fair and affordable; nutritionally adequate, safe and healthy; while optimizing natural and human resources (Figure 1). The key dimensions of sustainable diet emphasize the interdependencies of food procurement, production, consumption, requirements and nutrient recommendations, needs, accessibility and availability in surrounding ecosystems. Therefore, sustainable diets can advocate the utilization of food resources with lower water and carbon footprints, and encourage utilization of agricultural biodiversity, particularly local and indigenous food resources [2]. Agricultural biodiversity is known to perform many closely interrelated environmental and socio-economic functions; among these are livelihood needs, food security, supporting resilient rural economies, productive and environmental sustainability [3]. Agricultural biodiversity is a multi-dimensional subject with utilization and management of the environment and its components resulting in producing economic and social benefits from various components of agricultural biodiversity. Agricultural biodiversity is a fundamental component of many farming systems dotted throughout the world and encompasses several types of biological entities tied to agricultural systems, including the following $[4,5]$ :

- i. genetic resources, the essential component of all living organisms,

- ii. edible plants and crops,

- iii. freshwater fish and livestock,

- iv. soil organisms which are important to soil structure, fertility, quality and health,

- v. variety of bacteria, fungi and insects which are crucial in controlling diseases and pests of animals and plants,

- vi. agroecosystem features and types required various ecosystem productivity processes, ecosystem stability and nutrient cycling, and

- vii. landscapes and undomesticated resources that are characterized by numerous ecosystem goods and services.

Two kinds of agricultural biodiversity are recognized: domesticated (managed) and non-domesticated (unmanaged) agricultural biodiversity. The cultivated agricultural biodiversity combined with their wild relatives are important as they supply local people with different types of genetic resources required for food and essential plant and animal products. People throughout the world consume about 7000 plant species, with 150 species regarded as commercially valuable, while 103 species provide 90 percent of the world's major food crops [6]. Research by FAO [7] reveals that more than 50 percent of the carbohydrates and proteins needed by the world's human population is provided by three food crops, namely rice, maize and wheat. But in Southern Africa and other marginal environments of developing agricultural economies, many less well-known plant species are consumed, domesticated and managed in home gardens contributing to the livelihood needs of the poor and to the development of agricultural biodiversity. Such plant species include S. rautanenii (Schinz) Radcl.-Sm., a multipurpose food, medicinal and timber plant species characterized by promising socio-economic potential for food security of local communities, poverty alleviation and meeting important livelihood needs in rural, peri-urban and marginalized areas in Southern Africa. S. rautanenii is a component of non-domesticated (unmanaged) agricultural biodiversity, with its fruits, seeds and other important plant parts collected mainly from the wild although in some countries in Southern Africa the species is domesticated and managed in home gardens. This review will add valuable literature on plant species that are important for local livelihood needs and income generation by the rural poor and those people living in marginalized areas in Southern Africa. Scientific evidence for the livelihood and health benefits of useful plant species such as S. rautanenii is important as this species will contribute towards 
environmental management, carbon sequestration by sustainable use and conservation of such species. This review evaluates the contribution of a useful plant species, S. rautanenii to sustainable diets, including nutritional, social, religious, provisioning and environmental issues. The literature reviewed in this study highlight the important issues required to strengthen the contribution of such useful plant species to sustainable diets, livelihood needs and environmental sustainability in rural, peri-urban and marginalized areas.

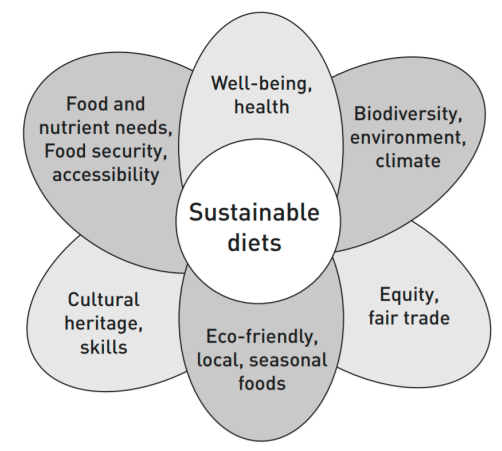

Figure 1. Venn diagram showing the key components of a sustainable diet [2].

\section{Materials and Methods}

Literature search for information relevant to the contribution of S. rautanenii to sustainable diets, livelihood needs and environmental sustainability in Southern Africa was carried out from June to December 2017. Emphasis was placed on literature from the geographical range of the species that included Namibia, Malawi, South Africa, Mozambique, the Democratic Republic of Congo, Tanzania, Botswana, Zambia, Angola and Zimbabwe. The information was obtained from the main online scientific sites including Science Direct, SciFinder, Pubmed, Google Scholar, Medline, and SCOPUS. Searches were also undertaken in the library, University of Fort Hare and the dissertation search engines like ProQuest, Open-thesis, OATD and EThOS. The keywords used in the search included "S. rautanenii", the synonym of the species "Ricinodendron rautanenii Schinz", English common names "false balsa", "featherweight tree", "manketti tree", "manketti nut tree" and "mongongo nut". Additional search was also carried out using the keywords "ethnobotany + S. rautanenii", "medicinal uses + S. rautanenii", "traditional uses + S. rautanenii", "indigenous knowledge + S. rautanenii", "local knowledge + S. rautanenii", "traditional ecological knowledge + S. rautanenii", "environmental sustainability + S. rautanenii", "livelihood needs + S. rautanenii" and "sustainable diets + S. rautanenii". A total of 41 articles matched the inclusion criteria and were included in the review (Figure 2).

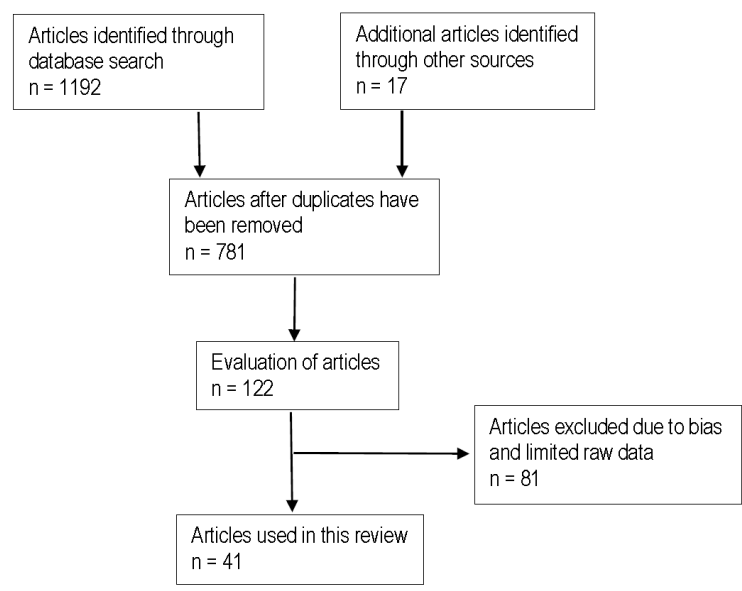

Figure 2. Flow diagram with the number of selected articles. 


\section{S. rautanenii Constitute an Essential Food Crop}

According to Robbins and Campbell [8] the nuts of S. rautanenii have been used as a staple food source in the Kalahari desert in Botswana for at least 7000 years. The nuts form the mainstay of the vegetable diet of the !Kung bushmen of Botswana who are known to consume between 100 and 300 of these nuts per day [9-11]. The pulp of the drupe-like fruits, fresh or naturally dried is available all year round providing an estimated $40 \%$ of the total diet of local people in north western Botswana [12,13]. Similar findings were obtained by Hailwa [14] who evaluated the importance of non-timber forest products (NTFPs) in Namibia and showed that $S$. rautanenii is a valuable source of food to several people in the San community in the country, particularly those who are not involved in farming activities. Research by Saxon and Chidiamassamba [15] showed that the consumption of the nuts increases in difficult times such as droughts and during civil wars. Therefore, the fruits of S. rautanenii constitute an important food source in Southern Africa, regarded as an essential component of the diet of some people in the region, especially the poor and those living in marginalized areas. Fruits and nuts of $S$. rautanenii are also widely used in Botswana, Malawi, Mozambique, Namibia, Zambia and Zimbabwe $[12,15-20]$ as a strategy by the rural people to reduce food insecurity and as an important source of supplementary food particularly during drought.

The nut or seed is the most popular part of $S$. rautanenii fruit. It is eaten raw or dried and most pleasant when roasted [11]. A meal or paste is sometimes made by pounding the nuts or porridge or fermented alcoholic drink is made from the pulp (mesocarp) $[10,11,20]$. S. rautanenii fruits are famous for producing liquor in Namibia, where water is added to peeled or unpeeled fruits and leaving the mixture to ferment for at least three days up to two weeks in a plastic bucket. The fermented juice is then heated and distilled to produce fermented alcoholic drink [20]. The kernel is also used as a food thickener agent for stews and soups that accompany meat, fish and vegetables $[10,11,15]$. The oil extracted from the nuts is used for cooking [21,22]. The fruit pulp and nut of $S$. rautanenii is highly nutritious by virtue of high amounts of carbohydrates, protein and vitamins (Table 1), which are comparable to other well-known indigenous fruits with edible kernels such as Sclerocarya birrea (A. Rich.) Hochst. [23,24] and a commercial fruit crop, cashew nuts, Anacardium occidentale L. [25]. In terms of mineral content, the mesocarp and seed tissues of $S$. rautanenii are excellent sources of essential minerals such as phosphorus, magnesium, potassium, iron, sodium, copper, zinc and calcium [10]. Several amino acids and fatty acids (Table 2) have been identified from the mesocarp and seed tissues of $S$. rautanenii $[10,17,23-28]$. Compared to conventional nut and oil crops such as A. occidentale, S. rautanenii is a rich source of macro- and micronutrients (Tables 1 and 2). Reference is also made to the recommended dietary allowance (RDA) representing the average daily intake of essential nutrients that are sufficient to meet the nutrient requirements of a health person (Tables 1 and 2). When compared with the World Health Organization (WHO) protein RDA values, S. rautanenii demonstrated low proportions of several essential amino acids, a trend also demonstrated by A. occidentale and S. birrea [23-25]. The carbohydrates, protein, vitamins, different minerals, amino acids and fatty acids identified from the fruit pulp and seed of $S$. rautanenii imply that the species is essential in meeting the nutritional needs of local communities at risk of food insecurity, macro- and micronutrient malnutrition. According to the United Nations International Children's Emergency Fund (UNICEF) [29], malnutrition is a major challenge in Eastern and Southern Africa where 40\% of minor children, particularly those under the age of five years are suffering from it. Research by Chivandi et al. [30] showed that edible fruits obtained from indigenous fruit trees like $S$. rautanenii are important sources of macro- and micronutrients and health enhancing chemicals that have chemical, pharmacological and biological properties that mitigate some of the medical and biological effects of malnutrition. Unfortunately, indigenous edible fruits like $S$. rautanenii are currently underutilized, neglected by researchers, agricultural extension officers and policy makers. Their promotion could assist in a protracted fight against malnutrition, domestication and environmental sustainability in Southern Africa. These are some of the initial steps that can be taken in trying to address the SDGs including goals 1, 2, 3, 12 and 15 . 
Table 1. Nutritional composition of the mesocarp and seed tissues of S. rautanenii compared with nutritional values of kernels of $S$. birrea and A. occidentale and the recommended dietary allowance (RDA).

\begin{tabular}{|c|c|c|c|c|c|}
\hline \multicolumn{3}{|c|}{ S. rautanenii } & \multirow{2}{*}{ S. birrea } & \multirow{2}{*}{ A. occidentale } & \multirow{2}{*}{$\begin{array}{l}\text { Recommended Dietary } \\
\text { Allowance (RDA) }\end{array}$} \\
\hline Chemical Composition & Mesocarp & Seed & & & \\
\hline Ash $\%$ of dry weigh & 5.6 & 4.1 & $5.05 \pm 0.61$ & 2.5 & - \\
\hline Calcium g/100 g & 104 & 193 & $51.73 \pm 6.0$ & 41.0 & $1000-1300$ \\
\hline Copper g/100 g & 1.6 & 2.82 & $1.07 \pm 0.10$ & - & $1-2$ \\
\hline Energy value (kJ per $100 \mathrm{~g}$ ) & 1424 & 2692 & 1545.36 & 2525 & - \\
\hline Fat $\%$ of dry weigh & 1.2 & 57.3 & $1.30 \pm 0.15$ & - & 300 \\
\hline Fibre $\%$ of dry weigh & 2.5 & 2.5 & - & 3.6 & $25-38$ \\
\hline Fructose g/100 g & 0.5 & - & - & - & 130 \\
\hline Glucose g/100 g & 0.2 & - & $0.21 \pm 0.01$ & - & 130 \\
\hline Iron $\mathrm{g} / 100 \mathrm{~g}$ & 4.3 & 3.7 & $8.83 \pm 0.15$ & 5.7 & $8-15$ \\
\hline Magnesium g/100 g & 266 & 527 & $24.53 \pm 2.06$ & 248.8 & $310-320$ \\
\hline Moisture $\%$ of dry weight & 8.4 & 4.2 & - & 3.8 & - \\
\hline Nicotinic acid $\mathrm{mg} / 100 \mathrm{~g}$ & 4.79 & 0.31 & - & 1.31 & $16-35$ \\
\hline Phosphorus mg/100 g & 62.0 & 845 & $0.18 \pm 0.02$ & 502.5 & 1250 \\
\hline Potassium mg/100 g & 2666 & 673 & $44.54 \pm 0.41$ & 622.5 & 4700 \\
\hline Protein $\%$ of dry weigh & 9.4 & 26.0 & $3.31 \pm 0.10$ & 21.3 & 34 \\
\hline Riboflavin mg/100 g & 0.21 & 0.21 & - & 0.028 & $0.3-1.6$ \\
\hline Sodium $\mathrm{g} / 100 \mathrm{~g}$ & 1.86 & 3.1 & $14.88 \pm 6.0$ & 1.44 & 2300 \\
\hline Sucrose $\mathrm{g} / 100 \mathrm{~g}$ & 29.8 & - & $0.76 \pm 0.21$ & 6.3 & 130 \\
\hline Thiamine $\mathrm{mg} / 100 \mathrm{~g}$ & 0.49 & 0.31 & - & 0.477 & $1-2$ \\
\hline$\alpha$-tocopherol (Vitamin E) & - & 29 & - & 0.45 & 20 \\
\hline$\gamma$-tocopherol $\mathrm{mg} / 100 \mathrm{~g}$ & - & 536 & & 5.07 & 20 \\
\hline Total carbohydrate $\mathrm{g} / 100 \mathrm{~g}$ & 72.9 & 5.9 & $90.35 \pm 0.77$ & 20.5 & 130 \\
\hline Vitamin C mg/100 g & 14.7 & - & $0.49 \pm 0.3$ & 0.13 & 46 \\
\hline Zinc g/100 g & 1.79 & 4.09 & $2.96 \pm 1.0$ & 5.3 & $8-11$ \\
\hline
\end{tabular}

Source: Wehmeyer [10]; Hassan et al. [23]; Mariod and Abdelwahab [24]; Rico et al. [25].

Table 2. Amino acids and fatty acid composition of seeds and mesocarp tissues of $S$. rautanenii compared with nutritional values of kernels of $S$. birrea and A. occidentale and the RDA.

\begin{tabular}{|c|c|c|c|c|c|}
\hline \multicolumn{3}{|c|}{ S. rautanenii } & \multirow{2}{*}{ S. birrea } & \multirow{2}{*}{ A. occidentale } & \multirow{2}{*}{$\begin{array}{l}\text { Recommended Dietary } \\
\text { Allowance (RDA) }\end{array}$} \\
\hline Chemical Composition & Mesocarp & Seed & & & \\
\hline \multicolumn{6}{|l|}{ Amino acids } \\
\hline Alanine $\mathrm{g} / 100 \mathrm{~g}$ & 0.4 & 1.0 & 1.81 & 0.82 & - \\
\hline Arginine $\mathrm{g} / 100 \mathrm{~g}$ & 0.7 & 3.5 & 6.12 & 2.22 & - \\
\hline Aspartic acid g/100 g & 0.4 & 2.4 & 4.87 & 1.89 & - \\
\hline Cysteine $\mathrm{g} / 100 \mathrm{~g}$ & - & 0.1 & 4.1 & - & $28-43$ \\
\hline Glutamic acid g/100 g & 0.7 & 4.2 & 1.42 & 4.60 & - \\
\hline Glycine $\mathrm{g} / 100 \mathrm{~g}$ & 0.2 & 1.2 & 2.75 & 0.89 & - \\
\hline Histidine $\mathrm{g} / 100 \mathrm{~g}$ & 0.1 & 0.7 & 2.68 & 0.47 & $21-32$ \\
\hline Isoleucine $\mathrm{g} / 100 \mathrm{~g}$ & 0.2 & 0.7 & 3.3 & 0.80 & $28-43$ \\
\hline Leucine $\mathrm{g} / 100 \mathrm{~g}$ & 0.2 & 1.4 & 4.8 & 1.47 & $63-93$ \\
\hline Lysine $\mathrm{g} / 100 \mathrm{~g}$ & 0.2 & 0.7 & 1.18 & 0.97 & $58-89$ \\
\hline Methionine $\mathrm{g} / 100 \mathrm{~g}$ & 0.8 & 0.4 & 4.1 & 0.37 & $28-43$ \\
\hline Phenylalanine $\mathrm{g} / 100 \mathrm{~g}$ & 0.2 & 1.3 & 2.5 & 0.93 & $54-84$ \\
\hline Proline $\mathrm{g} / 100 \mathrm{~g}$ & 0.2 & 1.2 & 2.06 & 0.75 & - \\
\hline Serine $\mathrm{g} / 100 \mathrm{~g}$ & 0.3 & 1.3 & 2.43 & 1.11 & - \\
\hline Threonine $\mathrm{g} / 100 \mathrm{~g}$ & 0.2 & 1.0 & 1.31 & 0.74 & $32-49$ \\
\hline Tyrosine $\mathrm{g} / 100 \mathrm{~g}$ & 0.1 & 0.5 & 1.68 & 0.63 & $37-58$ \\
\hline Valine $\mathrm{g} / 100 \mathrm{~g}$ & 0.2 & 1.8 & 3.06 & 1.12 & 10 \\
\hline \multicolumn{6}{|l|}{ Fatty acid } \\
\hline Arachidic acid (C20:0) \% & - & $0.2-0.6$ & - & 0.63 & 0.1 \\
\hline$\alpha$ eleostearic acid (C18:3) \% & - & 21.7 & - & & - \\
\hline$\beta$ eleostearic acid (C18:3) \% & - & 21.7 & - & & - \\
\hline Erucic $(\mathrm{C} 22: 1 \mathrm{n} 9) \%$ & - & $21.5 \pm 0.84$ & 0.38 & - & - \\
\hline Gondoic acid (C20:1) \% & - & 0.3 & $0.14-0.70$ & & - \\
\hline Linoleic acid (C18:2) \% & - & $37.8-51.9$ & $4.3-5.93$ & 17.77 & 6.7 \\
\hline Linolenic acid (C18:3) \% & - & 26.6 & 0.12 & 0.13 & 1.4 \\
\hline Margaric acid (C17:0) \% & - & 0.08 & - & - & - \\
\hline Myristic acid (C14:0) \% & - & $0.03 \pm 0.01$ & $0.1-2.12$ & - & - \\
\hline
\end{tabular}


Table 2. Cont.

\begin{tabular}{ccccccc}
\hline \multicolumn{2}{c}{ S. rautanenii } & & S. birrea & A. occidentale & $\begin{array}{c}\text { Recommended Dietary } \\
\text { Allowance (RDA) }\end{array}$ \\
\cline { 1 - 4 } Chemical Composition & Mesocarp & Seed & & - & - \\
Myristoleoic acid (C14:1n7) \% & - & $0.01 \pm 0.0$ & - & - & - \\
Oleic acid (C18:1n9) \% & - & $15.2 \pm 1.53$ & $4.13-67.3$ & - & - \\
Oleic acid (C18:1) \% & - & $17.7-24.4$ & & - & - \\
Palmitic acid (C16:0) \% & - & $8.8-11.95$ & $14.2-22.6$ & 10.02 & - \\
Palmitoleic acid (C16:1) \% & - & 0.06 & - & - & - \\
Stearic acid (C18:0) \% & - & $3.0-11.77$ & $8.84-50.8$ & 8.93 & - \\
\hline
\end{tabular}

Source: Wehmeyer [10]; Chivandi et al. [17]; Hassan et al. [23]; Mariod and Abdelwahab [24]; Rico et al. [25]; Mitei et al. [26]; Gwatidzo et al. [27,28].

\section{Medicinal Uses and Ethnopharmacology of S. rautanenii}

Local people in Southern Africa use different parts of S. rautanenii as herbal medicine for back pain, cancer, fever, infertility, measles, skin diseases, skin cleanser, skin moisturizer, sleepless nights, sores and stomachache (Table 3). In Mozambique and Zimbabwe, the hard outer nut shells of S. rautanenii fruits are popular as divining "bones" [15,31]. Different plant parts of S. rautanenii widely used as herbal concoctions have medicinal value probably due to their inherent constituents such as alkaloids, anthraquinones, coumarins, flavonoids, phenols, saponins and triterpenes that have been identified from the bark and root extracts of the species [32]. The author found total phenolic compound content of the root and bark of $S$. rautanenii to be $48.6 \pm 1.2$ and $41.4 \pm 1.2$ gallic acid equivalent (GAE) $\mu \mathrm{g} / \mathrm{mL}$, respectively. Alkaloid content of the bark and roots of $S$. rautanenii was $2.1 \%$ and $9.5 \%$, respectively. Saponin content of the bark and roots of $S$. rautanenii was $13.1 \%$ and $2.0 \%$, respectively [32]. Dushimemaria [32] evaluated antioxidant activities of $S$. rautanenii extracts using 2,2'-azino-bis(3-ethylbenzothiazoline-6-sulphonic acid) (ABTS) assay. Antioxidant activities of the bark and root extracts of $S$. rautanenii were 200 and 900 ascorbic acid equivalent (AAE) $\mu \mathrm{g} / \mathrm{mL}$, respectively [32]. The author also evaluated anti-protease activities of $S$. rautanenii extracts using the GIBEX screens-to-nature assay. This study reports high anti-protease activity of all methanolic extracts derived from S. rautanenii. Dushimemaria [32] evaluated anti-cancer activities of $S$. rautanenii extracts against renal, breast and melanoma cancer cell models. The melanoma cell line UACC-62 displayed significant sensitivity towards the aqueous root and bark extracts of the species with low half maximal inhibitory concentration $\left(\mathrm{IC}_{50}\right)$ values of $116.7 \mu \mathrm{g} / \mathrm{mL}$ and $128.7 \mu \mathrm{g} / \mathrm{mL}$, respectively. The authors also reported that organic root extract of the species demonstrated significant activities towards UACC-62 melanoma cell line with $\mathrm{IC}_{50}$ value of $102.6 \mu \mathrm{g} / \mathrm{mL}$ which was not significantly different from the $\mathrm{IC}_{50}$ value of $102.4 \mu \mathrm{g} / \mathrm{mL}$ demonstrated by the MCF-7 breast cancer cells. Dushimemaria [32] evaluated cytotoxicity activities of $S$. rautanenii extracts against a human fetal lung fibroblast cell lines. The aqueous and organic root extracts of the species demonstrated some activities with the $\mathrm{IC}_{50}$ values of $315.5 \mu \mathrm{g} / \mathrm{mL}$ and $444.8 \mu \mathrm{g} / \mathrm{mL}$ against the human fetal lung fibroblast cell, respectively. Similarly, Dushimemaria and Mumbengegwi [33] evaluated antiproliferative properties of $S$. rautanenii extracts using the brown planaria (Dugesia dorotocephala). Treatment of D. dorotocephala using the bark extracts of the species revealed growth inhibiting properties at high extract concentration when compared with the negative control, while growth promoting properties were exhibited at lower extract concentration when compared with the negative control. Dushimemaria [32] evaluated toxicity activities of $S$. rautanenii extracts in vivo in fresh water flatworm planaria (D. dorotocephala). This depicted that $S$. rautanenii organic bark extract negatively affected planaria regeneration, indicating that as extract concentration increased, the cytotoxicity effects of $S$. rautanenii bark extracts were more visibly seen as affecting planaria regeneration in comparison to low extract concentration. S. rautanenii root extract affected the planaria growth in a concentration dependent manner. These anti-cancer and antiproliferative activities demonstrated by $S$. rautanenii extracts $[32,33]$ support the traditional use of the species as herbal medicine against cancer in Namibia [32]. 
The oil extracted from S. rautanenii is also a highly valued emollient in Southern Africa that nourishes and protects the skin and therefore is widely used as a cream, lotion and ointment [34]. In Southern Africa, the oil extracted from S. rautanenii is mainly applied on the skin because of its hydrating properties, regenerating and restructuring attributes that contribute to ultraviolet (UV) protection for the skin and hair [35]. Zimba et al. [36] argued that the presence of vitamin E, and fatty acids such as linoleic and eleostearic acids [10], makes the oil useful for hydrating and protecting the skin which may play a vital role in the treatment of atopic diseases, eczema and other diseases where the oil results in the reduction of inflammation and promotion of tissue regeneration and cellular repair, leading to reduced itching, redness and scarring, as well as prevention of keloids. The $S$. rautanenii has naturally high zinc content and, for years, the San communities of the Kalahari region in Namibia have used it to safeguard themselves from the desert sun; it also moisturizes and conditions the skin offering additional protection from the sun [36]. Skin supplementation with anti-oxidants usually result in the reduced photo damage and photo aging due to free-radical oxidative stress [37]. Zimba et al. [36] argued that the oil extracted from $S$. rautanenii is important for aromatherapy and cosmetic applications mainly because they result in long shelf life and oxidative stability of the skin. It has been shown that products rich in fatty acids such as linoleic acid boost antimicrobial properties of the skin, especially in people suffering from atopic dermatitis. In acneic skin, particularly in follicular hyperkeratinisation, topical application of $S$. rautanenii seed oil result in reduced production of oleic acid and squalene leading to normal production of linoleic acid levels [36]. However, detailed phytochemical studies of $S$. rautanenii and its pharmacological properties aimed at illustrating the correlation between its ethnomedicinal uses and pharmacological properties are required. Such detailed chemical, nutritional and toxicological evaluations are required before S. rautanenii can be used as an alternative dietary source, herbal medicine or source of aromatherapy products. There is need for extensive in vitro and in vivo experiments to validate the existing pharmacological activities of the species. Toxicological evaluations of the species are required aimed at establishing any potential toxic components and side effects associated with utilization of the species as food, traditional medicine and/or emollient.

Table 3. Ethnomedicinal uses of S. rautanenii.

\begin{tabular}{cccc}
\hline $\begin{array}{c}\text { Medicinal } \\
\text { Applications }\end{array}$ & Plant Parts Used & Country & References \\
\hline Back pain & Bark & Namibia & Elago and Tjaveondja [38] \\
Cancer & Not specified & Namibia & Dushimemaria [32] \\
Fever & Bark & Namibia & Elago and Tjaveondja [38] \\
Infertility & Not specified & Namibia & Msangi [39] \\
Measles & Leaves & Namibia & Cheikhyoussef and Embashu [19] \\
Skin diseases & Aerial parts & South Africa & Juliani et al. [40]; Vermaak et al. [41]; Lall and Kishore [42] \\
Skin cleanser & Aerial parts & South Africa & Juliani et al. [40]; Vermaak et al. [41]; Lall and Kishore [42] \\
Skin moisturizer & Aerial parts & South Africa & Juliani et al. [40]; Vermaak et al. [41]; Lall and Kishore [42] \\
Sleepless nights & Bark & Namibia & Elago and Tjaveondja [38] \\
Sores & Not specified & Namibia & Dushimemaria et al. [43] \\
Stomachache & Bark & Namibia & Elago and Tjaveondja [38] \\
\hline
\end{tabular}

\section{Integration of S. rautanenii into Formal Agricultural Production Systems}

S. rautanenii has multiple uses, including oil production, source of edible fruits and kernels, source of timber and wood as well as different plant parts used as herbal medicines. These multiple uses of the species and its social, religious and ecological functions in the ecosystem resulted in some households sparing the species during land clearing for farming and maintaining the species in arable agricultural fields in many local communities of Southern Africa. Research by Van den Eynden [44] revealed that plant management in agricultural arable fields like home gardens can be divided into two major groups: cultivated (planted) or tolerated (not planted). Cultivated species are cared for and tendered by home garden owners during their entire life cycle [44]. They are usually sown as seeds and require regular watering and weeding to promote quick growth. Tolerated species are those plant species that are deliberately spared by home garden owners and their households during digging, 
weeding and land clearing activities in agricultural fields or home gardens because of the benefits or usefulness they provide to households and the environment [45]. Tolerated species like S. rautanenii are tendered and conserved in home gardens and agricultural fields, and they also grow naturally in the wild. S. rautanenii also makes an excellent live fence and grow vigorously from truncheons, or coppice shoots, cutting considerable time to fruit bearing, compared to time it would take if they are grown from seeds [16,46]. In Zambia, S. rautanenii is widely cultivated and used as a live fence around arable agricultural fields and animal enclosures [36]. The National Council for Scientific Research (NCSR) in Zambia has a Tree Improvement Research Centre which has several projects throughout the country focusing on the domestication of S. rautanenii using plant tissue culture techniques [47]. In Namibia, Du Plessis [48] advocated for the domestication and marketing of S. rautanenii in the country. Research by Keegan and van Staden [11] showed that the seeds of S. rautanenii are dormant and the removal of the endocarp is a prerequisite for germination. Therefore, applications of ethrel (2-chloroethane phosphonic acid) and gaseous ethylene to seeds of $S$. rautanenii resulted in rapid germination. The authors found that gibberellic acid was effective only once the testa had been scarified. These results suggest that the embryos are unable to resume growth owing to a hormonal imbalance in which ethylene plays a primary role in seed germination of S. rautanenii [11].

Domestication of $S$. rautanenii is necessary for the diversification of subsistence agriculture in southern Africa, which could play a big role in attaining and achieving the SDGs, particularly goals $1,2,3,12$ and 15. At the same time, the species can also be used to halt and reverse the increasing degradation of ecosystems in Southern Africa and contribute towards carbon sequestration while providing socio-economic and livelihood needs to local communities. For plant species such as S. rautanenii that are in high demand and characterized by increasingly limited supplies, sustainable use of such species can be an effective conservation alternative. S. rautanenii is listed by Mark et al. [49] as one of the timber species that is at risk of disappearing because it is actively harvested for commercial trade. Similarly, the tree was designated a protected species in Namibia in the early 1990s in terms of the existing forest legislation since 1952 [50], probably because of its socio-economic importance as food, timber and herbal medicine. Over-exploitation, indiscriminant collection, uncontrolled deforestation and habitat destruction are all responsible for negatively affecting the population size of S. rautanenii. Therefore, to reach an effective compromise between conservation of the species on one hand and sustainable utilization on the other, serious consideration should be given to establishing commercially viable stands of large numbers of the tree in Malawi, Zambia, Botswana, Mozambique, Zimbabwe and Namibia where the species is widely used by local communities. The overall trend of useful plant loss observed in the past and the need to develop effective conservation strategies for such species has led to the emergence of several paradigms and principles of conservation. One of them is the principle of "conservation through use or through trade", an important conservation strategy aimed at providing monetary incentives or other forms of benefits to local communities for all species and habitats they are conserving and managing in a sustainable manner [13,51]. Such a conservation strategy can be applied to multipurpose species such as $S$. rautanenii throughout its distributional range. Research by Dovie et al. [52] revealed that when such a conservation approach is adopted, it is more successful as a livelihood strategy when social and community beliefs and rights are understood and addressed in the conservation programmes.

\section{Commercial Potential of S. rautanenii}

Research by Bennett [53] showed that about 200,000 people are currently employed in gathering S. rautanenii fruits and trading in this species, and its products have the potential of generating close to US\$20 million in Southern Africa. S. rautanenii and its products are traded in informal markets in Malawi, Mozambique, Zambia and Zimbabwe [54] while oil extracted from the species is exploited commercially in Botswana and Namibia [17]. In Zambia, the wood and timber obtained from the species is used in producing curios and other crafts that are marketed in tourist resorts [55]. Kivevele and Huan [56] evaluated the fuel properties of biodiesel from S. rautanenii seeds and the authors 
found that, most of the determined fuel attributes of the species fulfilled the minimum chemical requirements of global biodiesel standards. The biodiesel produced from S. rautanenii seed oil may be used as a substitute of the common mineral diesel. Seed oil extracted from $S$. rautanenii has over the years been used in producing lubricants, soaps and personal cosmetic care products, as well as health products used in the topical treatment of various ailments and conditions such as hair dandruff, muscle spasms, varicose veins and wounds $[17,36]$. Therefore, commercialization of the oil derived from the species may result in several economic activities that positively impact local communities and may contribute to household economy and their livelihoods. Nemarundwe et al. [57] argued that promotion of natural resources utilization should not only emphasize the need to sustainably use these resources to meet the livelihood needs of local people, but also encourage communities to effectively manage their natural resources and protect the environment. Creating markets for S. rautanenii will ultimately lead to "conservation through use or through trade" resulting in increased awareness and economic importance associated with the species. It is evident that commercialization, formal trade and socio-economic activities will result in a positive impact on local communities, conservation, and the natural products industry as a whole [57].

The land where $S$. rautanenii trees are indigenous and growing is known not to be suitable for agricultural activities like cultivation of crops [56]. The development of additional uses and external markets for S. rautanenii will benefit local communities by providing several local, regional and international markets for the products derived from the species. Shackleton et al. [58] argued that the growing interest in the use and commercialization of NTFPs is a result of studies that have shown natural products as being crucial alternatives to agricultural products which may be very low due to poor and erratic rainfall. Therefore, commercialization of productions derived from NTFPs such as S. rautanenii will result in creating economic opportunities to people in rural areas and marginalized areas, thus improving household income and employment opportunities. The majority of poor people in rural, marginal and peri-urban areas have no access to industries and other economic activities such that during off-cropping season they have no other sources of income other than harvesting and selling S. rautanenii fruits. Nemarundwe et al. [57] argued that trade in natural products such as $S$. rautanenii should be promoted since this commodity is more accessible to the poor, there are minimal barriers to entry and there are few and in some cases no harvesting costs other than labor and time. For harvesting and processing of $S$. rautanenii and its products, local people already possess the required skills. Therefore, trade in $S$. rautanenii builds on rich traditional ecological knowledge, skills and technologies which may contribute towards the promotion of new externally facilitated products and markets.

Small and medium-sized enterprises (SMEs) and local communities that are marketing S. rautanenii at a commercial scale still rely on the traditional methods to crack the species' nuts to obtain the oil-rich kernels. This rudimentary system for cracking the nut is a major barrier to commercializing of S. rautanenii products. According to Nemarundwe et al. [57] traditional cracking of S. rautanenii nuts involve hitting the nut between two stones, a bigger stone below and a smaller one used as a hammer. Kernel extraction is a slow, tedious, difficult, laborious and a delicate operation that requires skill, experience and patience as use of excessive force may result in shattering the kernel leading to low output [57]. The same nut-cracking method is used to extract the oil-rich kernels of S. birrea commonly known as marula, a species of significant commercial prominence in Southern Africa. One of the S. birrea products that is widely traded at local, regional and international markets is marula cream liqueur. Marula cream liqueur is exported to nearly 150 countries and is the world's second most popular cream liqueur to Baileys Irish cream [59]. Therefore, the current extraction methods of $S$. birrea and S. rautanenii kernels should be improved, ideally with semi-manual equipment that will retain manual labor and also benefit the local economy. For S. rautanenii to realize its full local, regional and international market potential, there is need for development of necessary infrastructure, processing technology, product packaging and preservation, government support in terms of extension services, policies and guidelines related to horticultural development and marketing. 


\section{Conclusions}

This article explored the potential contribution of $S$. rautanenii as a source of multiple ecosystem goods and services that are essential components of the 2030 SDGs approved by the United Nations and sets out for the period 2016-2030. Sustainable diets and food systems are being explored throughout the world as a strategy to orient collective action towards the eradication of hunger and malnutrition in communities and the fulfilment of other SDGs [60]. Several socio-economic and ecological activities are supported by wise utilization of S. rautanenii in Southern Africa, including food production, fuel, source of timber and wood as well as different plant parts used as traditional medicines and proving several ecosystem services. Results of this study support previous observations made by Bharucha and Pretty [61] that wild foods make an enormous contribution towards reducing the existing supply and demand of food and nutritional security gap as multipurpose species like S. rautanenii provide health, ecosystem services and socio-economic benefits to communities that depend on them. Therefore, there is need to diversify crops in the arable agricultural systems to include the lesser known and underutilized species such as S. rautanenii in order to strengthen the food and ecological networks of local communities. National governments and local communities in Southern Africa need to consider the significance of $S$. rautanenii to food security, macro- and micronutrient contribution of the species and its ecological and provisioning role.

Acknowledgments: The author would like to express his gratitude to the National Research Foundation, South Africa (NRF grant number T398) and Govan Mbeki Research and Development Centre (GMRDC, grant number (169), University of Fort Hare for financial support to conduct this study.

Conflicts of Interest: No conflict of interest is associated with this work.

\section{References}

1. United Nations (UN) General Assembly. Resolution Adopted by the General Assembly on 25 September 2015; United Nations (UN): New York, NY, USA, 2015. Available online: http:/ / www.un.org/en/development/ desa/population/migration/generalassembly/docs/globalcompact/A_RES_70_1_E.pdf (accessed on 10 October 2017).

2. Food and Agriculture Organization (FAO). Sustainable Diets and Biodiversity. Directions and Solutions for Policy, Research and Action. In Proceedings of the International Scientific Symposium, Biodiversity and Sustainable Diets. United Against Hunger, Rome, Italy, 3-5 November 2010; Food and Agriculture Organization (FAO): Rome, Italy, 2010.

3. Pimbert, M. Sustaining the Multiple Functions of Agricultural Biodiversity; Gatekeeper Series No. 88; International Institute for Environment and Development (IIED): London, UK, 1999.

4. Thrupp, L.A. Linking agricultural biodiversity and food security: the valuable role of agrobiodiversity for sustainable agriculture. Int. Aff. 2000, 76, 265-281. [CrossRef] [PubMed]

5. Cromwell, E.; Cooper, D.; Mulvany, P. Agriculture, biodiversity and livelihoods: Issues and entry points for development agencies. In Living off Biodiversity: Exploring Livelihoods and Biodiversity Issues in Natural Resources Management; Koziell, I., Saunders, J., Eds.; International Institute for Environment and Development (IIED): London, UK, 2001; pp. 75-112, ISBN 978-1-899825-67-7.

6. Zhou, M. Promote conservation and use of underutilized crops. In Plant Genetic Resources Conservation and Use in China, Proceedings of the National Workshop on Conservation and Utilization on Plant Genetic Resources, Beijing, China, 25-27 October 1999; Gao, W., Rao, V.R., Zhou, M., Eds.; Institute of Crop Germplasm Resources, Chines Academy of Agricultural Sciences (CAAS): Beijing, China; International Plant Genetic Research Institute (IPGRI) Office for East Asia: Beijing, China, 2001; ISBN 92-9043-463-5.

7. Food and Agriculture Organization (FAO). Report on the State of the World's Plant Genetic Resources for Food and Agriculture; Food and Agriculture Organization (FAO): Rome, Italy, 1996.

8. Robbins, L.H.; Campbell, A.C. Prehistory of mongongo nut exploitation in the western Kalahari desert, Botswana. Botsw. Notes Rec. 1990, 22, 37-42. 
9. Palmer, E.; Pitman, P. Trees for Southern Africa Covering all Known Indigenous Species in Republic of South Africa, South West Africa, Botswana, Lesotho and Swaziland; A.A. Balkema: Cape Town, South Africa, 1972; ISBN 0869610333.

10. Wehmeyer, A.S. Ricinodendron rautanenii Schinz, Addendum 1: The Nutrient Composition of Manketti Fruit9 Southern African Plants, No. 4463,000-0010; Government Printer: Pretoria, South Africa, 1976.

11. Keegan, A.B.; van Staden, J. Dormancy and germination of the manketti nut Ricinodendron rautanenii Schinz. S. Afr. J. Sci. 1981, 77, 262-264.

12. Lee, R.B. Mongongo: The ethnography of a major wild food resource. Ecol. Food Nutr. 1973, 2, $307-321$. [CrossRef]

13. Peters, C.M.; Balick, M.J.; Kahn, F.; Anderson, A.B. Oligarchic forests of economic plants in Amazonia: Utilization and conservation of an important tropical resource. Conserv. Biol. 1989, 3, 341-349. [CrossRef] [PubMed]

14. Hailwa, J. Non-Wood Forest Products of Namibia: Data Collected and Analysis for Sustainable Forest Management in ACP Countries-Linking National and International Efforts; Directorate of Forestry, Ministry of Environment and Tourism: Windhoek, Namibia, 1998.

15. Saxon, G.; Chidiamassamba, C. Indigenous Knowledge of Edible Tree Products: The Mungomu Tree in Central Mozambique; Food and Agriculture Organization (FAO): Rome, Italy, 2005.

16. Storrs, A.E.G. Know Your Trees: Some of the Common Trees in Zambia; Forestry Department: Ndola, Zambia, 1979; ISBN 9789105324052.

17. Chivandi, E.; Davidson, B.C.; Erlwanger, K.H. A comparison of the lipid and fatty acid profiles from the kernels of the fruit (nuts) of Ximenia caffra and Ricinodendron rautanenii from Zimbabwe. Ind. Crop. Prod. 2008, 27, 29-32. [CrossRef]

18. Van Wyk, B.; Gericke, N. People's Plants: A Guide to Useful Plants of Southern Africa; Briza Publications: Pretoria, South Africa, 2008; ISBN 9781875093373.

19. Cheikhyoussef, A.; Embashu, W. Ethnobotanical knowledge on indigenous fruits in Ohangwena and Oshikoto regions in Northern Namibia. J. Ethnobiol. Ethnomed. 2013, 9, 34. [CrossRef] [PubMed]

20. Misihairabgwi, J.; Cheikhyoussef, A. Traditional fermented foods and beverages of Namibia. J. Ethn. Foods 2017, 4, 145-153. [CrossRef]

21. Engelter, C.; Wehmeyer, A.S. Fatty acid composition of oils of some edible seeds of wild plants. J. Agric. Food Chem. 1970, 18, 25-26. [CrossRef] [PubMed]

22. Davis, J.B.; Kay, D.E.; Clark, V. Plants Tolerant of Arid, or Semi-Arid, Conditions with Non-Food Constituents of Potential Use; London Bookmark: London, UK, 1983.

23. Hassan, L.G.; Dangoggo, S.M.; Hassan, S.W.; Muhammad, S.; Umar, K.J. Nutritional and antinutritional composition of Sclerocarya birrea fruit juice. Niger. J. Basic Appl. Sci. 2010, 18, 222-228. [CrossRef]

24. Mariod, A.A.; Abdelwahab, S.I. Sclerocarya birrea (Marula), an African tree of nutritional and medicinal uses: A review. Food Rev. Int. 2012, 28, 375-388. [CrossRef]

25. Rico, R.; Bulló, M.; Salas-Salvadó, J. Nutritional composition of raw fresh cashew (Anacardium occidentale L.) kernels from different origin. Food Sci. Nutr. 2016, 4, 329-338. [CrossRef] [PubMed]

26. Mitei, Y.C.; Ngila, J.C.; Yeboah, S.O.; Wessjohann, L.; Schimidt, J. NMR, GC-MS and ESI-FTICT-MS profiling of fatty acids and triacylglycerols in some Botswana seed oils. J. Am. Oil Chem. Soc. 2008, 85, 1021-1032. [CrossRef]

27. Gwatidzo, L.; Botha, B.M.; McCrindle, R.I. Determination of amino acid contents of manketti seeds (Schinziophyton rautanenii) by pre-column derivatisation with 6-aminoquinolyl-Nhydroxysuccinimidyl carbamate and RP-HPLC. Food Chem. 2013, 141, 2163-2169. [CrossRef] [PubMed]

28. Gwatidzo, L.; Botha, B.M.; McCrindle, R.I. Fatty acid profile of manketti (Schinziophyton rautanenii) nut oil: Influence of extraction method and experimental evidence on the existence of $\alpha$-eleostearic acid. J. Cereals Oilseeds 2017, 8, 33-44. [CrossRef]

29. United Nations Children's Fund (UNICEF). UNICEF Eastern and Southern Africa: Young Child Survival and Development: Nutrition, 2017. Available online: https://www.unicef.org/esaro/5479_nutrition.html (accessed on 21 November 2017).

30. Chivandi, E.; Mukonowenzou, N.; Nyakudya, T.; Erlwanger, K.H. Potential of indigenous fruit-bearing trees to curb malnutrition, improve household food security, income and community health in sub-Saharan Africa: A review. Food Res. Int. 2015, 76, 980-985. [CrossRef] 
31. Gelfand, M.; Mavi, S.; Drummond, R.B.; Ndemera, B. The Traditional Medical Practitioner in Zimbabwe: His Principles of Practice and Pharmacopoeia; Mambo Press: Gweru, Zimbabwe, 1985; ISBN 9780869223505.

32. Dushimemaria, F. An Investigation into the Antineoplastic Properties of Schinziophyton rautanenii and Colophospermum mopane. Master's Thesis, University of Namibia, Windhoek, Namibia, 2014.

33. Dushimemaria, F.; Mumbengegwi, D.R. Proposition of a low cost field assay to determine antiproliferate properties of indigenous plants using Dugesia dorotocephala (brown planaria). Sci. Res. Essays 2015, 10, 144-149. [CrossRef]

34. Mohammad, A.; Mahmood, N. Taxonomic perspective of plant species yielding vegetable oils used in cosmetics and skin care products. Afr. J. Biotechnol. 2005, 4, 36-44. [CrossRef]

35. Gunstone, F.D. Bailey's Industrial Oil and Fat Products, 6th ed.; John Wiley \& Sons: New York, NY, USA, 2005; ISBN 9780471678496.

36. Zimba, N.; Wren, S.; Stucki, A. Three major tree nut oils of southern central Africa: Their uses and future as commercial base oils. Int. J. Aromather. 2005, 15, 177-182. [CrossRef]

37. Saral, Y.; Uyar, B.; Ayar, A.; Nazirogly, M. Protective effects of topical alpha tocopherol acetate on UVB irradiation in guinea pigs: Importance of free radicals. Physiol. Res. 2002, 51, 285-290. [PubMed]

38. Elago, S.N.; Tjaveondja, L.T. A comparative evaluation of the economic contributions and uses of Strychnos cocculoides and Schinziophyton rautanenii fruit trees to poverty alleviation in mile 20 village of Namibia. Agric. Food Sci. Res. 2015, 2, 25-31.

39. Msangi, J.P. Food Security Among Small-Scale Agricultural Producers in Southern Africa; Springer: New York, NY, USA, 2014; ISBN 978-3-319-09495-3.

40. Juliani, H.R.; Koroch, A.R.; Simon, J.E.; Wamulwange, C. Mungongo cold pressed oil (Schinziophyton rautanenii): A new natural product with potential cosmetic applications. Acta Hortic. 2007, 756, 407-412. [CrossRef]

41. Vermaak, I.; Kamatou, G.P.P.; Komane-Mofokeng, B.; Viljoen, A.M.; Beckett, K. African seed oils of commercial importance: Cosmetic applications. S. Afr. J. Bot. 2011, 77, 920-933. [CrossRef]

42. Lall, N.; Kishore, N. Are plants used for skin care in South Africa fully explored? J. Ethnopharmacol. 2014, 153, 61-84. [CrossRef] [PubMed]

43. Dushimemaria, F.; Mumbengegwi, D.R.; Böck, R. Indigenous knowledge of medicinal plants used for the treatment of cancer. In Indigenous Knowledge of Namibia; Chinsembu, K.C., Cheikhyoussef, A., Mumbengegwi, D.R., Kandawa-Schulz, M., Kasandra, C.D., Kazembe, L., Eds.; University of Namibia Press: Windhoek, Namibia, 2015; pp. 63-88, ISBN 9789991642055.

44. Van Den Eynden, V. Use and Management of Edible Non-Crop Plants in Southern Ecuador. Ph.D. Thesis, Ghent University, Ghent, Belgium, 2004.

45. Thomas, E.; Van Damme, P. Plant use and management in homegardens and swiddens: Evidence from the Bolivian Amazon. Agrofor. Syst. 2010, 80, 131-152. [CrossRef]

46. Leakey, R.R.B.; Mesén, J.F.; Tchoundjeu, Z.; Longman, K.A.; Dick, J.M.; Newton, A.; Matin, A.; Grace, J.; Munro, R.C.; Muthoka, P.N. Low-technology techniques for the vegetative propagation of tropical trees. Commonw. For. Rev. 1990, 69, 247-257. [CrossRef]

47. Lewanika, M.M. State of the art of biotechnology research in Zambia. Afr. Crop Sci. J. 1995, 3, $299-301$. [CrossRef]

48. Du Plessis, P. Indigenous Vegetables Development Proposal; National Agricultural Support Services Programm (NASSP) Report No. 005/2004; Ministry of Agriculture, Water and Rural Development: Windhoek, Namibia, 2004.

49. Mark, J.; Newton, A.C.; Oldfield, S.; Rivers, M. The International Timber Trade: A Working List of Commercial Timber Tree Species; Botanic Gardens Conservation International: London, UK, 2014.

50. Erkkila, A.; Siiskonem, H. Forestry in Namibia, 1850-1990; Silva Carelica 20; University of Joensuu: Joensuu, Finland, 1992; ISBN 951-708-010-7.

51. Wild, R.G.; Mutebi, J. Conservation through Community Use of Plant Resources: Establishing Collaborative Management at Bwindi Impenetrable and Mgahinga Gorilla National Parks, Uganda; United Nations Educational, Scientific and Cultural Organization (UNESCO): Paris, France, 1996.

52. Dovie, D.B.; Witkowski, E.; Shackleton, C.M. Knowledge of plant resource use based on location, gender and generation. Appl. Geogr. 2008, 28, 311-322. [CrossRef] 
53. Bennett, B. Natural Products: The New Engine for African Trade Growth: Consultancy to Further Develop the Trade Component of the Natural Resources Enterprise Programme (NATPRO). Regional Trade Facilitation Programme: Windhoek, Namibia, 2006.

54. Cunningham, A.B. African Medicinal Plants: Setting Priorities at the Interface between Conservation and Primary Health Care; People and Plants Working Paper 1; United Nations Educational, Scientific and Cultural Organization (UNESCO): Paris, France, 1993.

55. Chidumayo, E.N. Distribution and abundance of a keystone tree, Schinziophyton rautanenii, and factors affecting its structure in Zambia, southern Africa. Biodivers. Conserv. 2016, 25, 711-724. [CrossRef]

56. Kivevele, T.T.; Huan, Z. An analysis of fuel properties of fatty acid methyl ester from manketti seeds oil. Int. J. Green Energy 2015, 12, 291-296. [CrossRef]

57. Nemarundwe, N.; Ngorima, G.; Welford, L. Cash from the Commons: Improving Natural Product Value Chains for Poverty Alleviation. In Proceedings of the 12th Biennial Conference of the International Association for the Study of Commons (IASC), Cheltenham, UK, 14-18 July 2008. Available online: http: / / dlc.dlib.indiana.edu/dlc/bitstream/handle/10535/781/Nemarundwe_219401.pdf?sequence=1 (accessed on 8 October 2017).

58. Shackleton, S.; Shanley, P.; Ndoye, O. Invisible but viable: Recognising local markets for non-timber forest products. Int. For. Rev. 2007, 9, 697-712. [CrossRef]

59. Fellows, P.J.; Axtell, B. Opportunities in Food Processing: A Handbook for Setting up and Running a Smallscale Business Producing High-Value Foods; ACP-EU Technical Centre for Agricultural and Rural Cooperation, CTA: Wganingen, The Netherlands, 2014; ISBN 978-92-9081-556-3.

60. Meybeck, A.; Gitz, V. Sustainable diets within sustainable food systems. Proc. Nutr. Soc. 2017, 76, 1-11. [CrossRef] [PubMed]

61. Bharucha, Z.; Pretty, J. The roles and values of wild foods in agricultural systems. Philos. Trans. R. Soc. B Biol. Sci. 2010, 365, 2913-2926. [CrossRef] [PubMed]

(C) 2018 by the author. Licensee MDPI, Basel, Switzerland. This article is an open access article distributed under the terms and conditions of the Creative Commons Attribution (CC BY) license (http:/ / creativecommons.org/licenses/by/4.0/). 